\title{
GNATHODYNAMOMETER - A RELIABLE DEVICE FOR ASSESSING JAW BITE FORCE
}

\author{
Shushma $G^{1}$, Ramalingeshwara Kantly²
}

${ }^{1}$ Resident, Department of Dentistry, Koppal Institute of Medical Sciences, Koppal.

${ }^{2}$ Assistant Professor, Department of General Surgery, Koppal Institute of Medical Sciences, Koppal.

\begin{abstract}
BACKGROUND

The functional state of the masticatory system is best assessed by evaluating the bite force. The level of Maximum Bite Force (MBF) results from the combined action of the jaw elevator muscles; is modified by jaw biomechanics and reflex mechanisms. The measurement of bite force can provide useful data for the evaluation of jaw muscle function and activity. It is also an adjunctive value in assessing the performance of dentures or dental prosthesis. The bite force result depends on a number of factors, such as presence of pain and temporomandibular disorders, gender, age, craniofacial morphology and occlusal factors. In addition to these physiological factors, recording devices and techniques are important factors in bite force measurement. This article describes a device designed to measure patient jaw force that is accurate, simple and highly modular. We have vividly explained in detail about the development of a bite force device, Gnathodynamometer in this study. The device reported here represents the physiological use of a mechanical measuring device that has enhanced for human oral usage where it can be used to assess the complex function of human bite force and functional response of various cranio-mandibular structures associated with it.
\end{abstract}

\section{MATERIALS AND METHODS}

40 volunteer subjects ( 20 male and 20 female) of same age group ( 25 to 30 years) are included in this study and were asked to bite the steel fork part of the device as strong as possible in between the molars. Mean of the three readings are taken as MBF.

\section{RESULTS}

Mean MBF in males is $550.8 \mathrm{~N}$ and in females is $490.6 \mathrm{~N}$.

\section{CONCLUSION}

The gnathodynamometer is a simple device, easy to measure MBF even by trained health assistants. The advantages of this device are its accuracy, simplicity, ease of manufacturing and cost effectiveness.

\section{KEYWORDS}

Gnathodynamometer, Jaw Biting Force, Masticatory System.

HOW TO CITE THIS ARTICLE: Shushma G, Kantly R. Gnathodynamometer - a reliable device for assessing jaw bite force. J. Evolution Med. Dent. Sci. 2016;5(102):7488-7490, DOI: 10.14260/Jemds/2016/1695

\section{BACKGROUND}

The functional status of the masticatory system is determined by assessing the bite force. The biting force is generated by the action of the associated musculature of mandible and maxilla, ultimately transmitted through the teeth on the material which is being bitten or chewed.(1) The variation in the MBF values depends on many subject related as well as technically related factors. (2) Individual factors may be biomechanical, physiological and craniofacial morphological variable such as bite position, bite rise and unilateral or bilateral biting, facial morphology, state of dentition, functional disturbances of the masticatory system and head posture at the time of measurement.(3-5)

Technical factors depend on the measuring method and the mechanical characteristics of the bite force recording system. A wide range of devices have been used to measure

Financial or Other, Competing Interest: None.

Submission 15-11-2016, Peer Review 08-12-2016,

Acceptance 15-12-2016, Published 22-12-2016.

Corresponding Author:

Dr. Shushma G,

Resident,

Department of Dentistry

Koppal Institute of Medical Sciences,

Koppal.

E-mail: kantlybmc@gmail.com

DOI: $10.14260 /$ jemds $/ 2016 / 1695$

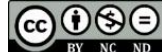

bite force(5) - bite fork, the strain gauge transducers, the gnathodynamometer, the foil transducers, the pressurised rubber tube, the pressure sensitive sheet and the force-sensing resistors.

The gnathodynamometer is one of the devices for measurement of biting force in human beings. It will provide an objective test of masticatory function. It is observed that the force range of most available gnathodynamometers is quite small - usually less than $200 \mathrm{~N}$ - whereas the maximum bite force in human beings can be up to $1200 \mathrm{~N}$. Measurement of bite force could not be accurately estimated from Electromyography (EMG) signals.(6)

The present study describes the design and assessment of MBF by the gnathodynamometer.

\section{MATERIALS AND METHODS}

The design of the gnathodynamometer [Image 1] comprises of its mechanical parts and the electronic circuit. The measuring element is in the form of a fork, which is inserted into the mouth. Fork is connected to the handle through a revolute joint, so that its angle with the handle may be changed. Strain gauges are bonded on the inner side of the prongs of the fork, towards the root. The wires emanating from the strain gauges are led to the electronic circuit through the handle. The bite is applied at the free end of the fork. A small projection is provided here, so that the bite is always at this location. Figure 1 shows the sketch of the measurement system. 


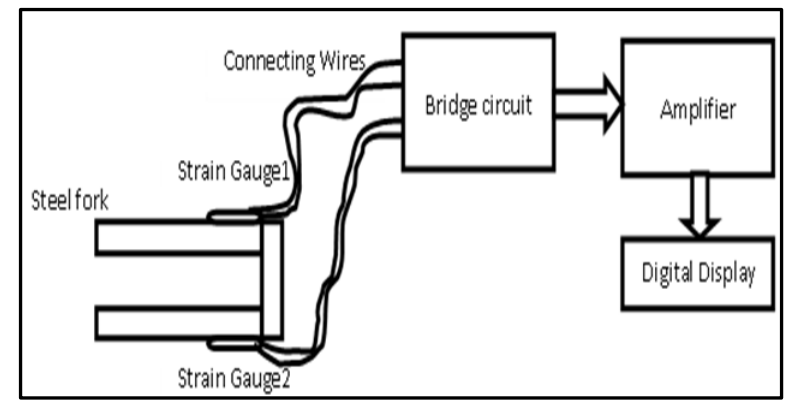

Image 1. Schematic Representation of Gnathodynamometer

The electronic instrument consists of Wheatstone bridge assembly, amplifier and the digital display. The Wheatstone bridge convert the change in resistance at steel forks to a proportional voltage. Upon biting the fork, both lower and upper prong outer surface elongates and results into increase in the resistance of both strain gauges. $R_{1}, R_{2}$ are strain gauges and $R_{3}, R_{4}$ are fixed resistances, $V_{\text {Ex }}$ is $5 \mathrm{~V}$ excitation voltage and $\mathrm{V}_{0}$ is the bridge output which will be connected to differential amplifier for amplification. The Wheatstone bridge arrangement is shown in Figure 2. Bridge is excited by a $5 \mathrm{~V}$ regulated supply and its output is $1.69 \mu \mathrm{V}$ for every $1 \mathrm{~kg}$ load on the fork (equals to $9.8 \mathrm{~N}$ force).

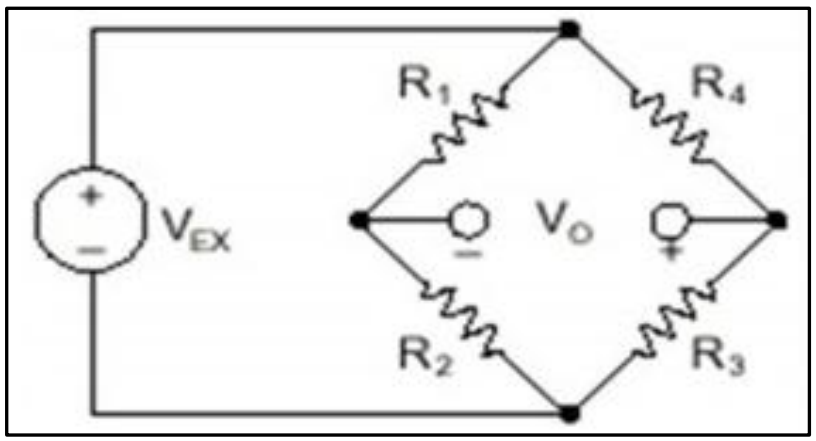

Image 2. Wheatstone Bridge Assembly

A differential amplifier is constructed using LM358 OPAMP IC as shown in Figure 3. LM358 is an 8 pin DIP IC with single supply. The output of the bridge is connected to this differential amplifier. The bridge output (-) and (+) are connected to $V_{1}$ and $V_{2}$ respectively. The amplifier output is connected to a Digital Panel Meter (DPM) with the range of 0 $200 \mathrm{mV}$. The gain of this amplifier $\left(\mathrm{R}_{1} / \mathrm{R}_{2}\right)$ is set by the position of a switch provided on the front panel of instrument, as explained below.

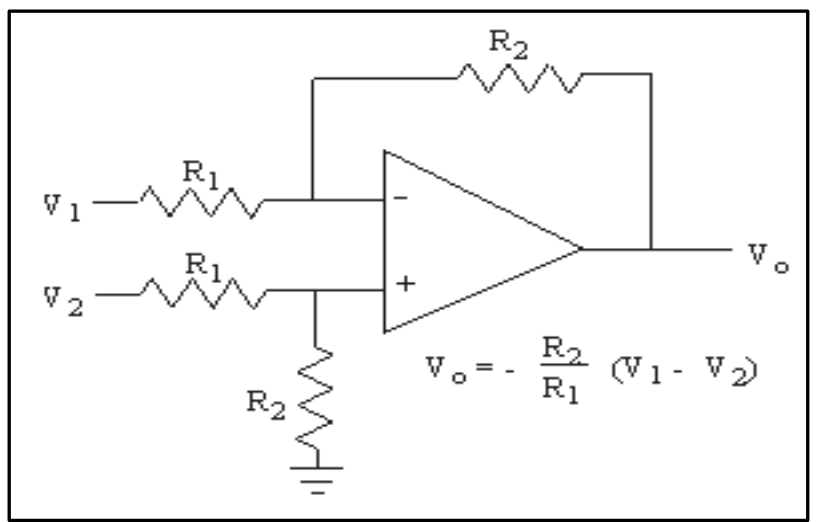

Image 3. Differential Amplifier
1. The switch in position " $A$ " (in measuring the bite force of anterior teeth) selects the $\mathrm{R}_{1}=2 \mathrm{M} \Omega$ and $\mathrm{R} 2=1 \mathrm{k} \Omega$ making the gain as 2000 , so that each $1 \mathrm{~kg}(\sim 9.8 \mathrm{~N})$ applied load on the fork results into $1.69 \mu \mathrm{V} \times 2000=3.38 \mathrm{mV}$. Hence, the display will show 3.38 . The multiplying factor is 2.9 . Upon multiplication, we get $9.8 \mathrm{~N}$.

2. The switch in position "P" (in measuring the bite force of posterior teeth) selects the $\mathrm{R}_{1}=1 \mathrm{M} \Omega$ and $\mathrm{R} 2=1 \mathrm{k} \Omega$ making the gain as 1000 , so that each $1 \mathrm{~kg}(\sim 9.8 \mathrm{~N})$ applied load on the fork results into $1.69 \mu \mathrm{V} \times 1000=1.69 \mathrm{mV}$. Hence, the display will show 1.69 . The multiplying factor is 5.8. Upon multiplication, we get $9.8 \mathrm{~N}$.

This way the instrument is calibrated by applying a known load by placing the fork in a UTM (Universal Testing Machine). We selected 40 volunteer subjects ( 20 male and 20 female) of same age group (25 to 30 years) are included in this study. All individuals had full complement of permanent teeth and well aligned with stable occlusion relationship and had no temporomandibular joint disorders and no previous history of trauma. The subjects were seated on a chair with head unsupported and were asked to bite as strong as possible. The device is placed between the molar teeth to record MBF and then the patients are asked to bite into the device at full jaw capacity [Image 2]. Mean of the three readings are taken as MBF. The data were recorded and analysed according to statistical variance and calculations.

\section{RESULTS}

Our study shows following observations,

1. The mean MBF of the men was $550.8 \mathrm{~N}(\mathrm{SD}=44.5)$ with the range of 510.8 to $634.6 \mathrm{~N}$.

2. The mean MBF of the women was $490.6 \mathrm{~N}(\mathrm{SD}=40.7)$ with the range of 441.6 to $520.8 \mathrm{~N}$.

\begin{tabular}{|c|c|c|}
\hline Subjects & Mean MBF & SD \\
\hline Male $(\mathrm{n}=20)$ & $550.8 \mathrm{~N}$ & 44.5 \\
\hline Female (n=20) & $490.6 \mathrm{~N}$ & 40.7 \\
\hline \multicolumn{2}{|c|}{ Table 1 } \\
\hline
\end{tabular}

\section{DISCUSSION}

Bite force is one indicator of the functional state of the masticatory system that results from the action of jaw elevator muscles modified by the craniomandibular biomechanics. ${ }^{(7)}$ Determination of individual bite force level has been widely used in dentistry, mainly to understand the mechanics of mastication for evaluation of the therapeutic effects of prosthetic devices and to provide reference values for studies on the biomechanics of prosthetic devices. ${ }^{(8)}$ In addition, bite force has been considered important in the diagnosis of the disturbances of the stomatognathic system.(9)

Measuring bite forces to evaluate treatment modalities became increasingly popular. It is being applied for,

- Measuring functional outcome after fracture reduction.

- Measuring bite forces and contact areas before and after distraction osteogenesis.

- Evaluating the functional outcome in denture wearers.

- Evaluating the functional outcome in implant retained prosthesis wearers.

- Measuring level of comfort after periodontal surgeries.

- As an aid to diagnosis for complicated orthodontic cases and thus plan further management. 
Currently, there are two types of bite force measurement techniques available, i.e. direct and indirect. Direct techniques include use of suitable transducer that can be placed between a pair of teeth. This direct method of bite force measurement appears to be convenient way to measure the submaximal force. An indirect method includes use of functional relationship between bite force and physiological variables as these variables are known to be functionally related to the bite force. (10)

The device which is used to measure biting force in our study is gnathodynamometer [Image 1]. The design constraints for such devices are size, shape, safety, loading, comfort, hygiene and range of force to be applied. A suitable mechanical structure using an elastic material is used to convert applied force into a deformation/deflection. The most common structure for such application is a fork shaped steel member. One or more strain gauges are cemented to the surface of each prong to sense the deformation caused by applied biting force. The strain gauges are sensors which convert the applied strain (deformation) into resistance. These strain gauges are used in a bridge circuit to convert variation in resistance to corresponding voltage. The voltage output is numerically correlated to the applied force by calibration process. Calibration is done with a standard Universal Testing Machine (UTM) in the laboratory. This is the framework of gnathodynamometer designed entirely in our study here. A similar calibration has been reported by Waltimo and Kononen,(11) but it has an inherently different design.

The human bite force recorded in our study lies within the calibration range. As explained above the reliability and validity using the state of the art gnathodynamometer in our study is as good as documented in other studies. ${ }^{(12,13)}$

\section{CONCLUSION}

The gnathodynamometer is a simple device, easy to measure MBF even by trained health assistants. It provides accurate and reproducible measurements. It is also a cost-effective device. Our observation also shows that men produced greater MBF than women.

\section{REFERENCES}

1. Hagberg C. Assessments of bite force: a review. J Craniomandib Disord 1987;1(3):162-9.

2. Koc D, Dogan A, Bek B. Bite force and influential factors on bite force measurements: a literature review. Eur J Dent 2010;4(2):223-32.

3. Alhaija ESA, AlZoubi IA, Al Rousan ME, et al. Maximum occlusal bite forces in Jordanian individuals with different dentofacial vertical skeletal patterns. Europ J Orthod 2010;32(1):71-7.

4. Sakaguchi K, Mehta NR, Abdallah EF, et al. Examination of the relationship between mandibular position and body posture. Cranio 2007;25(4):237-49.

5. Helkimo E, Carlsson GE, Helkimo M. Bite force and state of dentition. Acta Odontol Scand 1977;35(6):297-303.

6. Proeschel PA, Morneburg T. Task-dependence of activity/ bite-force relations and its impact on estimation of chewing force from EMG. J DENT RES 2002;81(7):464-8.

7. Bakke M. Bite force and occlusion. Semin Orthod 2006;12(2):120-6.

8. Fernandes CP, Glantz PO, Svensson SA, et al. A novel sensor for bite force determinations. Dent Mater 2003;19(2):11826.

9. Calderon PS, Kogawa EM, Lauris JR, et al. The influence of gender and bruxism on the human maximum bite force. J Appl Oral Sci 2006;14(6):448-53.

10. Ferrario VF, Sforza C, Zanotti G, et al. Maximal bite force in healthy young adults as predicted by surface electromyography. J Dent 2004;32(6):451-7.

11. Waltimo A, Kononen M. A novel biteforce recorder and maximal isometric biteforce values for healthy young adults. Scand J Dent Res 1993;101(3):171-5.

12. Linderholm $\mathrm{H}$, Wennstrcjm A. Isometric bite force and its relation to general muscle forge and body build. Acta Odonlol Scand 1970;28(5):679-89.

13. Atkinson HF, Shepherd RW. Masticatory movements and the resulting force. Arch OralBiology 1967;12(2):195-202. 